\title{
LA ESPADA DE LA INDEPENDENCIA: AGENCIA DE LOS OBJETOS, MATERIALIDAD Y RECURSOS POLÍTICOS EN EL PROCESO DE PATRIMONIALIZACIÓN ENTRE LOS MAPOYO (VENEZUELA)
}

\author{
Elis Meza ${ }^{1}$ \\ Lúcio Menezes Ferreira²
}

\section{RESUMEN}

Las dinámicas que rigen los procesos de activación patrimonial están fuertemente imbuidas por la gestión de las especificidades de los contextos nacionales. En el caso de Venezuela, donde durante por casi dos décadas se maneja un discurso Bolivariano, resulta notable como recurso político la posesión intergeneracional de una espada que el "Padre de la Patria", Simón Bolívar habría entregado a los Mapoyo como recompensa por su participación en la Guerra de Independencia de principios del siglo XIX. Argumentamos que el capital simbólico asociado a la rememoración de este evento junto a la materialidad de la espada como evidencia de su autenticidad, ha tenido influencia en el reconocimiento patrimonial de los Mapoyo y la otorgación de la titularidad territorial. Resaltamos tanto la agencia imbricada en la espada como la actuación de los Mapoyo en la utilización de este "recurso escaso" para avanzar sus intereses, en el contexto de la inserción gubernamental en un relato legitimador de su proyecto ideológico.

Palabras clave: activación patrimonial, materialidad, bolivarianismo, territorialidad indígena, mapoyo.

\section{RESUMO}

As dinâmicas que regem os processos de ativação patrimonial estão fortemente imbuídas pela gestão das especificidades dos contextos nacionais. No caso da Venezuela, onde por quase duas décadas se maneja um discurso Bolivariano, é notável o uso, como recurso político, da possessão inter-regional de uma espada que o "Pai da Pátria, Simón Bolivar, teria entregue aos Mapoyo como recompensa por sua participação na Guerra da Independência do começo do século XIX. Argumentamos que o capital simbólico associado à rememoração desse evento, junto à materialidade da espada, a qual evidencia sua autenticidade, tem influenciado no reconhecimento patrimonial dos Mapoyo e na outorga de sua titularidade territorial. Ressaltamos tanto a agência estabelecida pela espada, como a

1'Doutoranda em Antropologia pela UFPEL.

2Departamento de Antropologia e Arqueologia da UFPEL; investigador do CNPq. Contato: lucio.menezes@pq.cnpq.br

\begin{tabular}{|l|l|l|l|l|l|l|} 
(C) Rev. Arqueologia Pública & Campinas, SP & v. 10 & n. 3 & p. $91-113$ & OUT. 2016 & ISSN 2237-8294
\end{tabular}




\section{Revista de Arqueologia Pública}

atuação dos Mapoyo na utilização desse "recurso escasso, para avançar seus interesses no contexto da inserção governamental em um relato legitimador de seu projeto ideológico.

Palavras-chave: ativação patrimonial, materialidade, bolivarianismo, territorialidade indígena, mapoy

\section{ABSTRACT}

The dynamics reigning on cultural heritage's activation processes are strongly imbued in the specificities of national contexts. In the case of Venezuela, where has been handled by Bolivarian discourse in the past two decades, it is remarkable the use, as a political resource, of a sword that the "country's founding father", Simon Bolivar, would have delivered to Mapoyo as a reward for their participation in the War of Independence in the early nineteenth century. We argue that the symbolic capital associated with the commemoration of this event, with the materiality of the sword showing its authenticity, has influenced the cultural heritage recognition of Mapoyo, and the granting of his territorial ownership. We emphasize both the agency established by the sword, as the performance of Mapoyo to use of this "scarce resource" to advance their interests in the context of the government's inclusion in legitimating account of his ideological project.

Keywords: heritage activation, materiality, bolivarianism, indigenous territoriality, mapoyo.

\section{Introducción: Planteando Problemas y Premisas}

L'exigence à laquelle répondent les objets anciens est celle d'un être définitif, un être accompli. Le temps de l'objet mythologi que, c'est le parfait: $c^{\prime}$ est ce qui a lieu dans le présent comme ayant eu lieu jadis, et qui, par cela même est fondé sur soi, 'authentique' (BAUDRILLARD, 1968: 91-2).

Es innegable la afirmación de una "proliferación" contemporánea y mundial de memorias y de procesos de patrimonialización (TORNATORE, 2009; CANDAU, 2011). Sin embargo, éstas se insertan en contextos nacionales específicos por lo que también se relacionan a proyectos políticos diversos y a una "multiplicación de apropiaciones" según palabras de Tornatore (2009:18). Algunos autores, como Bortolotto (2015), hablan de creativas traducciones de los standares internacionales para mostrar que las experiencias locales nos muestran complejas interacciones. De hecho, admitir que "el espacio en el que circulan las personas está atravesado por fuerzas diversas" (ORTIZ, 1998: 38), nos lleva a pensar en términos de las variaciones contextuales. Allí donde ha sido planteada la globalización como una fuerza que irremediablemente acabaría con la diversidad cultural, encontramos certera la percepción de Gnecco (2015) que nos dice que la constitución 


\section{Revista de Arqueologia Pública}

contemporánea del capitalismo encuentra en la heterogeneidad un espacio privilegiado de reproducción, a la vez que da lugar a la domesticación local de los discursos globales, siendo muchas veces mediada por la negociación de la materialidad. De acuerdo con Sahlins (1994) en esto también tenemos que tener en cuenta la agencia de individuos determinados, que en coyunturas específicas gestionan poder simbólico, basado en el reconocimiento de la diferencia o en la coexistencia pactada (STRAVAKAKIS, 1999). No obstante, no son únicamente las personas que determinan los avatares de "lo social", sino que como una profusa literatura arqueológica y antropológica indica - y el presente caso de estudio concuerda plenamente - también los objetos deben ser vistos como practicantes de un rol activo en la condición patrimonial (HODDER, 2014; JONES, 2010; LATOUR, 2005).

Para los $\mathrm{Mapoyo}^{3}$, grupo indígena del sur de Venezuela, la estrecha relación con un elemento específico de su "patrimonio arqueológico" ha sido de enorme relevancia. Durante varias generaciones han celosamente custodiado una espada que en el siglo XIX les habría sido entregada por Simón Bolívar como reconocimiento a la participación que algunos miembros del grupo tuvieron en la Guerra de Independencia, y que acompañaba a la otorgación de tierras. La posesión de este objeto y la capacidad del mismo para movilizar capital simbólico fue decisivo para que dada la actual coyuntura política de Venezuela, y valiéndose del lenguaje patrimonial, las "tierras ancestrales" Mapoyo fueran finalmente reconocidas por el Estado venezolano en 2013.

\footnotetext{
${ }^{3}$ Resulta difícil establecer si en efecto se puede hablar de "los Mapoyo" en lo que respecta a las memorias que registran los etnógrafos y las que reivindican actualmente los líderes de la comunidad. Un artículo de Henley nos ilustra este punto, al decir: "la mayor parte de los datos etnográficos aquí presentados nos fueron suministrados por un solo informante, el capitán del grupo, Juan Sandoval, de 68 anos. A juicio de los mismos Mapoyo, el capitán es la única persona que tiene conocimientos amplios de las tradiciones culturales del grupo, puesto que éstas han caído en desuso y olvido" (HENLEY, 1975: 29). Aún así, por cuestiones retóricas y políticas, decidimos mantener este denominativo.
} 


\section{Revista de Arqueologia Pública}

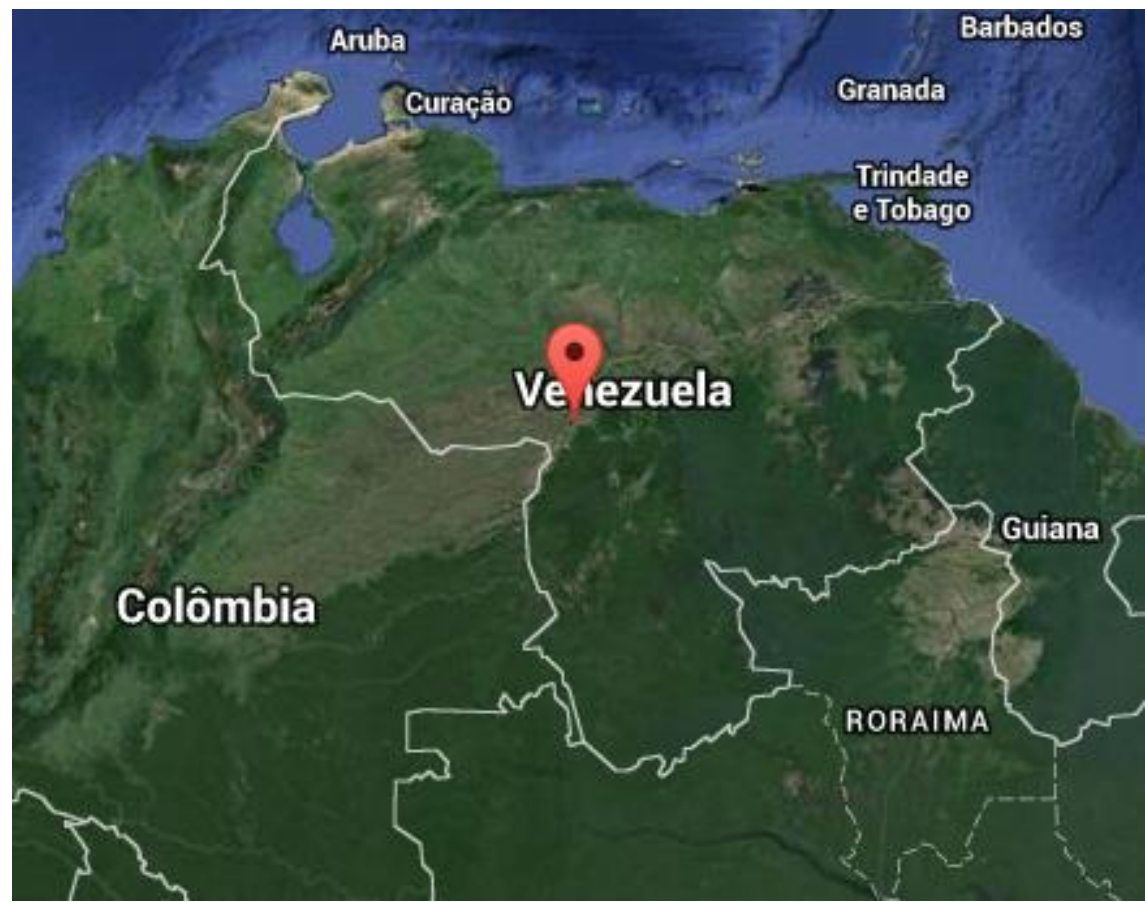

Figura 1: Mapa 1. Ubicación de El Palomo, principal asentamiento Mapoyo. Imagen tomada de https://www.google.com.br/maps/place/Palomo,+Venezuela/@2.3765789,-

73.7303005,3095378m/data=!3m1!1e3!4m2!3m1!1s0x8dd86003bbf7648f:0x567bb69c50cb9fa8

Como señala Fields en Comaroff y Comaroff (2010: 6), "raramente se atribuyen motivos propiamente políticos a los "grupos milenares". Pero esto no quiere decir que estos no hagan uso de estrategias políticas para adelantar sus propias agendas. Tal planteamiento guía nuestro entendimiento de cómo los Mapoyo se han convertido en uno de los grupos indígenas venezolanos con mejores estrategias de relacionamiento con la sociedad nacional, particularmente a través de su vinculación con diversas instancias estatales.

Haciendo una breve retrospectiva, cuando Cruxent (1948), una de las figuras más resaltantes en la historia temprana de la antropología y arqueología venezolana, escribió en su informe sobre el trabajo de campo que realizó en la zona del Orinoco para la Sociedad de Ciencias Naturales La Salle, que los Mapoyo estaban "al borde de la extinción", habría parecido inimaginable que 66 años después, ese grupo estaría representando el único patrimonio cultural nacional indígena elevado a "universal", al ser reconocido por el Instituto de Patrimonio Cultural de Venezuela y por la UNESCO.

Con la denominación de "La Tradición Oral Mapoyo y sus referentes simbólicos en el territorio ancestral" en la Lista de Salvaguarda Urgente, la imagen del Cacique Simón Bastidas estuvo en gran parte de los medios nacionales e internacionales y varios miembros \begin{tabular}{|l|l|l|l|l|l|l|}
\hline (C) Rev. Arqueologia Pública & Campinas, SP & v. 10 & n. 3 & p. 91-113 & OUT. 2016 & ISSN 2237-8294 \\
\hline
\end{tabular} 


\section{Revista de Arqueologia Pública}

de la comunidad participaron en eventos gubernamentales laudatorios. En muchos de estos espacios, el Cacique llevaba consigo la espada de Bolívar. Así, lo que principalmente figuró en el destaque mediático no fueron las tradiciones orales en general, sino como dicen Mosonyi y Suárez Luque (2009), el lugar de los Mapoyo como un "pueblo patriota olvidado". Podríamos decir que en el marco de las luchas por el reconocimiento de la etnicidad, la exaltación de cierta memoria colectiva autenticada materialmente, tiene un papel primordial, a la vez que son destacables las funciones políticas en la construcción de las narrativas del pasado que se escogen para la constitución de una tradición.

El manejo que los Mapoyo han logrado realizar de su Patrimonio, atravesando las complicadas "etnoburocracias" (BOCCARA y AYALA, 2012), nos muestra que contrario a la muerte cultural anunciada por etnógrafos apresurados, este grupo se ha dispuesto a gestionar políticamente su lugar en el panorama nacional, produciendo a su vez una configuración local de los discursos globales. El papel fundamental que ha jugado en tal panorama, el patrimonio cultural para la activación política de la etnicidad remite a que la inclusión o exclusión de manifestaciones culturales según los parámetros autorizados del patrimonio responde tanto a su trayectoria histórica relacional, como a la configuración de prácticas discursivas orientadas al control de los límites políticos dentro de los cuales se manejaría el patrimonio cultural. Siguiendo los planteamientos de Foucault, en la constitución de regímenes de verdad, se ejercita el poder en el entramado de instituciones, individuos, teorías, prácticas sociales y valores (FOUCAULT, 1994).

De acuerdo con Poulot "la razón patrimonial se autojustifica, trasciende sus condiciones sociales de producción y contribuye a tornarse matrices especificas para pensar el mundo y gobernar las modalidades de transmisión de la identidad" (POULOT, 2008: 36).En cuanto a sus sentidos más pragmáticos, el patrimonio, dice Lowenthal (2005) se ha convertido en la actualidad en el sine qua non de la identidad colectiva, tanto en lo que respecta a las luchas por reconocimiento y recursos por parte de los grupos sociales, como en la constitución de la nación como "comunidad imaginada".

De tal forma, Hodder (2010) plantea que el patrimonio cultural constituye nuevas formas de gobernanza y poder. Igualmente Ferreira argumenta (2013) que desde el siglo XVIII, el patrimonio cultural es uno de los elementos clave para la gubernamentalidad. Un ejemplo clásico de esto sería el interés de larga data de los Estados en propulsar la patrimonialización, tanto de sitios arqueológicos como de objetos, para la formación de un 


\section{Revista de Arqueologia Pública}

sentido de continuidad en la imaginación colectiva que permita su propia legitimización, fenómeno del cual no está exenta la actualidad venezolana (DIETLER, 1998).

Por otro lado, encontramos interesante que en la literatura colonial (s. XVIII- XIX) y luego en los trabajos antropológicos del siglo XX, se ha destacado la "confusión" sobre la identificación de los Mapoyo. Cronistas les han señalado en diversas ubicaciones geográficas y les han confundido con otros grupos ya desaparecidos como los Quaqua ${ }^{4}$. En el mapa etnográfico realizado por Lizarralde (1971) se les ha confundido con Panares. Así como también en el primer censo indígena fueron colocados bajo la categoría "otros" (OCEI, 1985). No obstante, luego de su proceso de activación patrimonial, los Mapoyo han figurado públicamente como la comunidad indígena que resguarda una de las seis espadas de las que se tiene conocimiento de haber pertenecido a Simón Bolívar. Encontramos que es un artefacto cuya "biografía" (KOPYTOFF, 1986) le permite destacarse como elemento que siendo un "recurso escaso" (APPADURAI, 2001) puede ser utilizado para lograr un posicionamiento simbólico y luego, pragmático mucho más conveniente que la sola implementación de la etnicidad para la articulación con el programa político nacional (RUETTE, 2011).

\footnotetext{
${ }^{4}$ En Henley (1975) hay una descripción detallada de este asunto.
} 


\section{Revista de Arqueologia Pública}

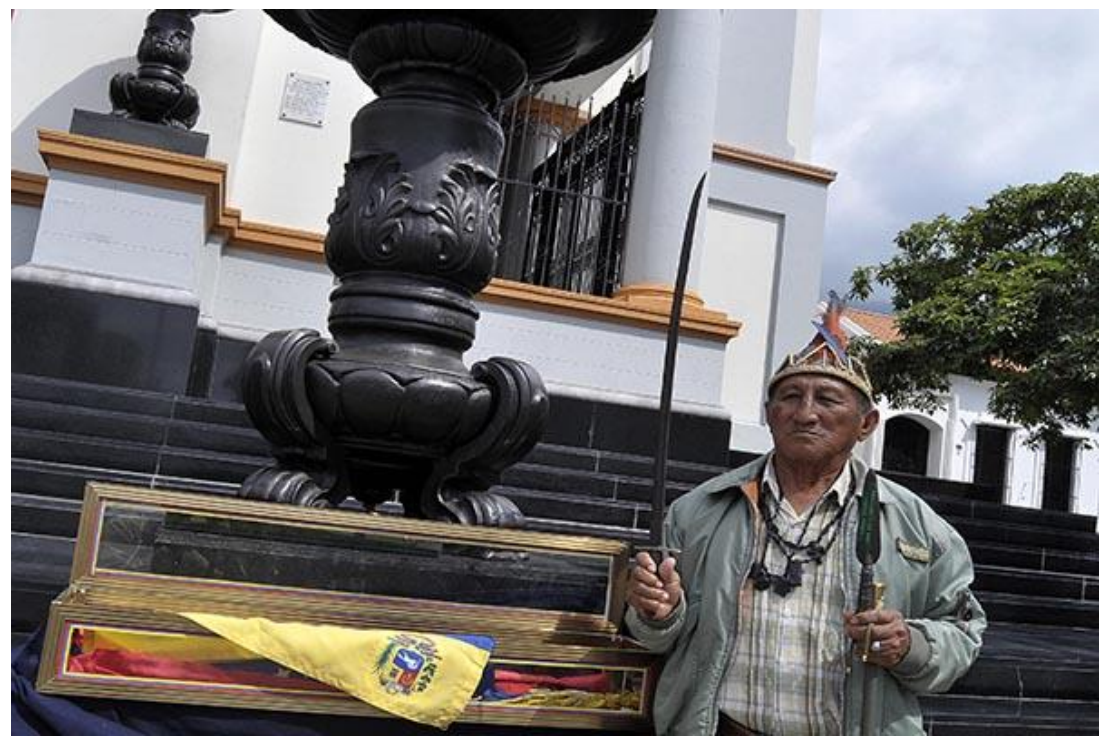

Figura 2: Capitán Simón Bastidas con la espada de Bolívar frente al Panteón Nacional. Imagen tomada de http://www.correodelorinoco.gob.ve/nacionales/pueblo-mapoyo-espada-bolivar-nos-hadefendido-por-decadas/. Accesado: 14 de abril de 2015.

Autores como García Canclini, lo colocan de esta manera: "el patrimonio existe como fuerza política en la medida en que es teatralizado" (GARCÍA CANCLINI, 1995: 151).Es así como mediante el Patrimonio también algunas comunidades indígenas han realizado un ejercicio de autodefinición de su etnicidad, cuestionando las representaciones externas de sus dinámicas históricas (p.ej. ABREU, 2012), a la vez que vinculando estas iniciativas al adelantamiento de demandas en torno a la territorialidad y otras formas de reconocimiento cultural. Estamos hablando entonces de una "zona de contacto" (CLIFFORD, 1991) en la cual los intereses indígenas pueden verse reflejados, pero también se cruzan en diatribas con los conceptos de indigeneidad presentes en las instituciones culturales. En tal sentido nos interesa abordar las negociaciones con el fin de entenderlos intereses de las partes involucradas.

Consideramos que el concepto de agencia puede ser útil para abordar las dialécticas en las relaciones de poder y especialmente, cómo son manejadas desde la posición de los llamados "grupos subalternos". Tomamos la definición de Kockelman (2007: 376), quien señala a la agencia como una especie de "relacionalidad mediadora", donde básicamente se hace una reformulación de la premisa clásica "nos hacemos a nosotros mismos, pero no bajo condiciones de nuestra escogencia"(MARX, S/D: 17). De tal manera, las acciones son contextualizadas entre las varias normas e recursos que les preceden, pero también les proporcionan oportunidades para que sean tanto restringidas como posibilitadas por la estructura. Entre estructura y agencia, debe destacarse que "el sistema \begin{tabular}{|l|l|l|l|l|l|l|}
\hline (C) Rev. Arqueologia Pública & Campinas, SP & v. 10 & n. 3 & p. 91-113 & OUT. 2016 & ISSN 2237-8294 \\
\hline
\end{tabular} 


\section{Revista de Arqueologia Pública}

de interacción-estruturación es continuamente reestruturado a través de la interacción" (KOCLEMAN, 2007: 376).

Esto nos conduce a que claramente, no es sólo el discurso desde arriba es el que cuenta, pues el patrimonio también ha visto su discurso global, indigenizado. Siendo uno de los elementos clave en tal movilización, la materialidad. Es a través de la acción de ciertos objetos que se posibilitan algunas relaciones entre personas y esto es de particular importancia en el ámbito político del patrimonio. En esto artículo, veremos como el caso de los Mapoyo ilustra estes procesos específicos de activación del patrimonio cultural. En la primera parte del artículo, profundizaremos el encunciado sobre la agencia de los objetos; en la segunda, mostraremos como los Mapoyo usaron la espada de Bolivar como recurso político y simbolico.

\section{Objetos y agencia: Comentarios sobre la relevancia de la materialidad para la activación patrimonial}

La tendencia prevaleciente en diversas tradiciones intelectuales durante buena parte del siglo XX, consideraba sensato oponer "palabras" y "cosas". De forma tal que la inercia propia de los objetos sólo podría ser puesta en movimiento a través de las personas. Se partía de una perspectiva durkheimiana que establecía que a partir de la estructura social se realizaba el ordenamiento del mundo de las cosas (APPADURAI, 1991). Tal noción antropocéntrica encontró una avalancha de críticas desde los años 80's, donde numerosos autores comenzaron a exponer la importancia de una antropología de las cosas, resaltando su "vida social" y su constitución política. Es lo que Hodder (2014) llama de "retorno a las cosas" (return to things), especialmente considerando que en muchas sociedades, e incluso en ciertos momentos de Occidente las cosas no han estado tan desvinculadas de la capacidad de actuar de las personas y de las palabras como. Así, era innegable la pertinencia de las discusiones académicas más comprehensivas, que dieran cuenta de cómo objetos y personas se co-constituyen unos a otros. Mauss (1950:25) lo expresaba así: "las almas se mezclan con las cosas; y las cosas con las almas" (souls are mixed with things; things with souls).

De igual manera, la línea de los estudios sobre cultura material ha señalado la relevancia de la construcción de las relaciones sociales a través de los objetos (APPADURAI, 1986; MILLER, 1998; DOUGLAS E ISHERWOOD, 1996; BEAUDRY et al., 1992). Aún otros sin inscribirse en este denominativo, ya realizaban una aproximación \begin{tabular}{|l|l|l|l|l|l|l|}
\hline (C) Rev. Arqueologia Pública & Campinas, SP & v. 10 & n. 3 & p. 91-113 & OUT. 2016 & ISSN 2237-8294
\end{tabular} 


\section{Revista de Arqueologia Pública}

similar (MINTZ, 1985; DIETLER, 1998; SAHLINS, 1994). Según Turgeon (2007: 25): "como os objetos materiais sobrevivem às pessoas, eles estruturam suas relações sociais com 0 tempo. Os objetos possuem suas próprias vidas, suas trajetórias, suas biografias que nós podemos reconstruir". Este razonamiento se enlaza con lo argumentado por Appadurai de que "aunque desde un punto de vista teórico los actores codifican la significación de las cosas, desde una perspectiva metodológica son las cosas-en-movimiento las que iluminan su contexto social y humano" (APPADURAI, 1986: 19).

Igualmente amplios han sido los debates sobre la imposibilidad de hablar de "cultura" sin referir a sus implicaciones materiales y por tanto, sobre la tautología de un término como "cultura material" (INGOLD, 2007). Adicionalmente décadas de críticas postcoloniales a la carga generalmente estática y esencialista del mismo concepto de "cultura" (CLIFFORD, 1988, ABU-LUGHOOD, 1991) ha llevado a algunos, como Miller (2005) a preferir la utilización de la noción de "materialidad". Por su parte, los partidarios de una fenomenología hermenéutica han colocado la experiencia corpórea como uno de los focos principales en la interpretación de las experiencias humanas concretas. Para Tilley, es claro que los artefactos concretizan performances metafóricas en el mundo de una manera que las palabras no poden hacerlo (TILLEY, 2002: 25).

Otra perspectiva que nos interesa examinar es la Teoría del Actor Red (Actor Network Theory) pues contribuye en el pensamiento sobre la agencia de los objetos, siendo esta una propiedad atribuible a humanos tanto como a no-humanos. Se acuna la idea de "agencia material" (KNAPPET Y MALAFOURIS, 2008), para establecer un alejamiento del dualismo inoperante entre materialidad y sociabilidad. De hecho, la "semiótica de la materialidad" claramente reconoce una fuerte ligación y codependencia práctica entre ambos ámbitos. Este entendimiento relacional que Latour llama "hibridización" se basa en el presupuesto de que los “objetos son hechos por redes sociales" (LATOUR, 2005: 248).

Dentro de un interés semiótico, Jones (2009) coloca la relevancia de aproximarnos al entendimiento de la contingencia que posibilita que ciertos objetos adquieran los significados que ostentan. El enfoque en el contexto que se evidencia en el libro seminal editado por Appadurai (1986), sugiere, como dijo Hodder posteriormente, que propiedades físicas o funcionales de los objetos pueden definir cómo éstos operan en la vida social (Hodder, 2014). O dicho de otro modo, cómo se insertan y transitan en "regímenes de valor" particulares. A pesar de tal compendio enfocarse en las "mercancías" resaltando el intercambio como fuente de valor, también nos ofrece una discusión pertinente a nuestra 


\section{Revista de Arqueologia Pública}

investigación, al referir a objetos que son colocados fuera de la esfera de "lo intercambiable", al tomar parte de una "singularización". En esto resalta el énfasis en sus configuraciones culturales dentro de un marco de relaciones específicas, es decir una biografía cultural, diferentemente de una biografía técnica o económica.

En resumen, se puede decir que los objetos están animados, vivos y palpitan entre las comunidades. Las cosas, así como las comunidades, tienen alma, están estructuradas e influyen en nuestros comportamientos (GOSDEN, 2005). Circunscriben memorias sociales, fijan calendarios, inspiran celebraciones (Jones 2007). Comunidades y cosas se encuentran enredadas (OLSEN, 2010; HODDER, 2012). Esto nos lleva a un entendimiento más sensible sobre la importancia de los objetos en diversos espacios e instituciones, entre ellos la activación patrimonial. Si las cosas despliegan una influencia en las personas y si podemos abordar sus biografías para situar el ejercicio de su agencia, entonces podemos entenderlas desde una perspectiva activa dentro de los procesos de selección de los elementos del pasado que a través de una gran variabilidad de criterios, instaura algunas cosas como objetos patrimoniales (CANDAU, 2012). Estos transcursos articulan especialmente tanto narraciones como objetos del pasado con construcciones políticas del presente, como es ya ampliamente documentado (LOWENTHAL, 1998). De tal manera, están profundamente imbricados el patrimonio, la materialidad y la política, como podemos ver en el caso de los Mapoyo.

\section{El panorama Bolivariano y la espada de los Mapoyo: ideología, materialidad y eficacia simbólica}

Venezuela ha vivenciado al menos desde 1999 la centralidad de la figura de Simón Bolívar dado que el imaginario sobre el "Libertador" que habría propulsado de transformaciones a lo interno de la República buscando una situación más igualitaria para los ciudadanos y que además se habría enfrentado a las opresiones externas, imperiales, fue primordial en el pensamiento de Hugo Chávez (1954-2013), conllevado a la apropiación del término "Bolivarianismo" para referir al proceso político "revolucionario" en Venezuela.

En el contexto Bolivariano, el multiculturalismo estatal ha producido un "proceso político sui generis" (ANGOSTO, 2010) de vinculación de movimientos sociales indígenas y "comunidades" con las esferas estatales y políticas públicas que parten de un relativamente reciente marco jurídico que, al menos "en el papel", favorece a los pueblos indígenas. Sin

\begin{tabular}{|l|l|l|l|l|l|l|}
\hline (C) Rev. Arqueologia Pública & Campinas, SP & v. 10 & n. 3 & p. 91-113 & OUT. 2016 & ISSN 2237-8294
\end{tabular}




\section{Revista de Arqueologia Pública}

embargo, resulta de mucha mayor relevancia la agencia que estos grupos puedan ejercer al establecer vinculaciones institucionales y personales.

De hecho, desde el Estado junto a las "memorias indígenas", también han sido resaltadas "memorias campesinas" y "memorias populares", que principalmente presenten componentes que puedan categorizarse dentro de conceptos genéricos de subalternidad en "resistencia" a la globalización, "insurgencia" al capitalismo y más ampliamente situarse dentro de manifestaciones "anti-imperialistas". Estas nominaciones han servido además para la incorporación de políticas identitárias de numerosos colectivos que se han mostrado a favor del gobierno y, realizando un despliegue de "tradicionalidad" han conseguido articularse a diversas políticas públicas, lo que, en la lógica bolivariana se transforma en beneficios para dichos grupos.

Para los Mapoyo ha sido mucho más relevante su "memoria de un pasado prestigioso" (CANDAU, 2011: 158). Según el recuento de Henley (1975), este grupo ayudó a las fuerzas republicanas a tomar un fuerte español situado en el cerro "El Castillo" que se encuentra sobre el rio Parguaza. La leyenda cuenta que el General Páez, al vadear el río Villacoa, tropezó con un grupo de Wánai para el momento trabajando para amos españoles. Páez solicitó que lo condujesen a él y sus tropas hasta la fortaleza española. Los indígenas llevaron a los republicanos por una pica escondida que desembocaba por el lado trasero del fuerte donde no había fortificaciones. El fuerte cayó sin un disparo, puesto que el ataque fue de sorpresa. En recompensa por este servicio, Páez llevó al jefe de los Wánai, Paulino Sandoval, a la tienda de Bolívar quien se encontraba acampado en la sabana. Bolívar les ofreció tres recompensas: dinero, ser comerciantes o el título de sus tierras. El jefe indígena escogió la última y Bolívar redactó un documento entregándoles las tierras, se comprometió a dejar una copia en "el ministerio" en Caracas. De acuerdo con las declaraciones de los informantes de Perera (1992) tal papel se perdió en el incendio que posteriormente tuvo lugar en la casa del Capitán. Ya para ese momento, finales de siglo XX y en las siguientes descripciones etnográficas, se evidencia la mención de la espada que Bolívar les habría entregado como muestra de su agradecimiento. Los Mapoyo se pueden situar entonces como descendientes de patriotas que fueron recompensados por el máximo héroe nacional con sus tierras. Lo destacan así: "nuestros ancestros escogieron la tierra".

Esta "memoria material", proyectada como "memoria activa" (MAZZUCHI e HEIDEN, 2011) para efectos de su patrimonialización, forma parte de la economía de la memoria, una aproximación de búsquedas memoriales, que a veces se confunde con 


\section{Revista de Arqueologia Pública}

afirmaciones identitárias. A su vez, la reivindicación de su memoria e identidad, se ancora al espacio - físico y alegórico - a través de la espada de Bolívar.

Por su parte, la constitución del discurso de la "revolución" se desdobla en múltiples referencias simbólicas que permite legitimación. Al posicionarse como una alternativa contra "el imperialismo", el elemento central que ha sido expuesto referente al pasado de la nación, ha sido la gesta independentista del siglo XIX, donde los "criollos" lucharon por liberar al país del imperio español y constituir una república independiente. En ese espíritu, ha sido tomado como lema: "la lucha continúa". Así pues, la historiografía oficial, junto a los medios de comunicación del Estado han elaborado una imagen del pasado de Venezuela centrada en la noción de "insurgencia", principalmente en base a las batallas en las que los patriotas resultaron vencedores. El personaje icónico es sin duda, Simón Bolívar, quien ya había sido utilizado, a principios de siglo XX por otro presidente, Juan Vicente Gómez, para bajo el resplandor de la elevación de Bolívar a personificación del Héroe Nacional, situar también su propia imagen en un panteón de notabilidad. Sería este uno de los antecedentes más resaltantes de la apropiación de Bolívar por el discurso de Hugo Chávez. Se trata de la continuidad en la forjación de la "identidad nacional", de la República Bolivariana de Venezuela. En ese contexto, los símbolos cohesionan memorias.

Es en esta línea de ideas que el embajador de Venezuela ante la Unesco, Luis Alberto Crespo, declaró luego de la noticia de la aprobación de la Tradición Oral Mapoyo en la Lista de Salvaguarda Urgente, que tal reconocimiento es un gran logro para la revolución y el pueblo, que permite revitalizar nuestra tradición oral indígena, ya que es un pueblo que tuvo una participación en nuestra guerra de Independencia, es por eso que forma parte de nuestra historia (CRESPO, 2014).

De esta manera, incluso cuando los Mapoyo no entran dentro de los parámetros comunes de la "indigeneidad", fueron presentados para su aprobación ante la UNESCO como el primer patrimonio indígena de Venezuela. Tal como menciona Angosto (2008: 28) "desde la esfera estatal y desde una parte importante del movimiento indígena se ha cultivado una asociación semántica de la resistencia indígena a la colonización y la alternativa bolivariana al neoliberalismo". Poco importa entonces para las instancias políticas que desde las visiones de los antropólogos de mediados de siglo XX, los Mapoyo fueran un grupo "aculturado" y poco importa también que posteriormente hayan sido analizados desde otras perspectivas, menos pesimistas y hasta reivindicativas. En lo que 


\section{Revista de Arqueologia Pública}

tiene que ver con el adelantamiento de un proceso de patrimonialización, es precisamente su componente de "memoria histórica" vinculada a la Independencia que resalta como fundamental para la activación del discurso nacionalista. Un "patrimonio patriótico" como dice Machuca (2010). A este respecto, Mosonyi (2009) investigador que ha servido como asesor del Estado, comenta que:

Las fuentes coloniales coinciden en presentar al pueblo mapoyo como guerrero y de espíritu rebelde, por el hecho de haber combatido permanentemente contra el Imperio Español para resguardar su independencia y libertad... En el caso de los Mapoyo (wánai)... se conservan importantes testimonios procedentes de una relación directa e íntima con el General Páez y el mismo Libertador Simón Bolívar (MOSONYI, 2009: 24).

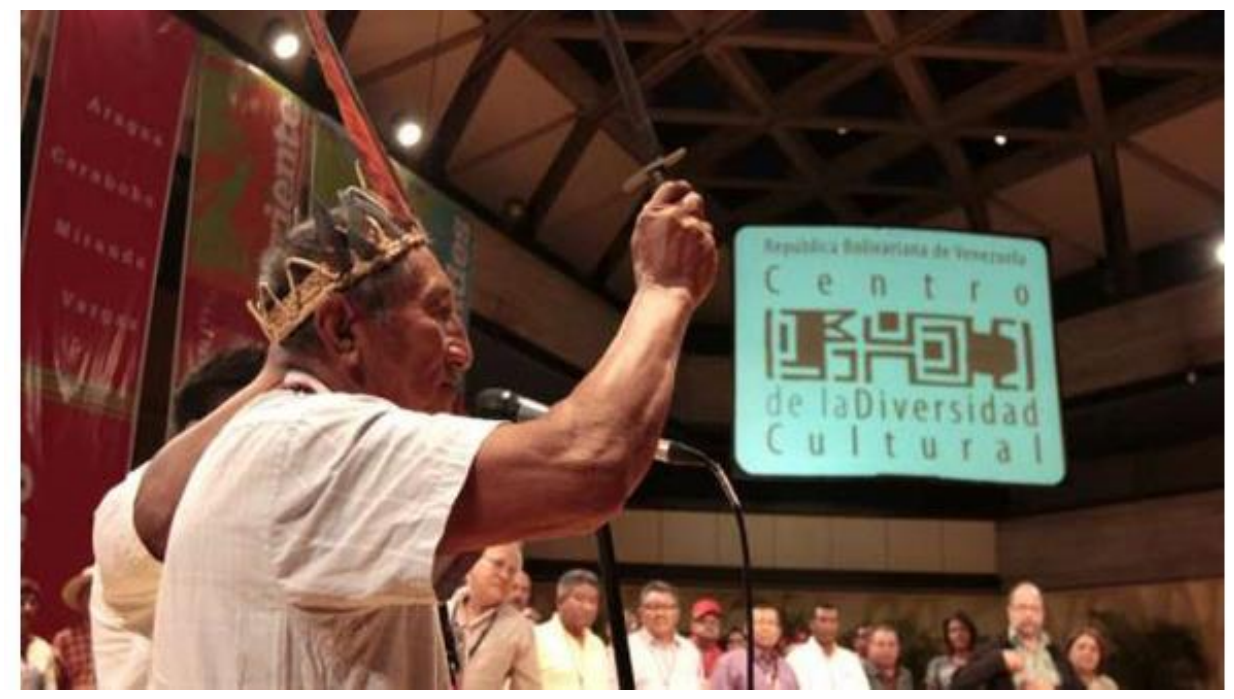

Figura 3: Capitán Simón Bastidas en un acto oficial, mostrando la espada de Bolívar y la daga de Páez. Imagen tomada de http://www.telesurtv.net/news/Proponen-preservar-memoria-cultural-de-losMapoyo-20140807-0081.html. Accesado: 2 de agosto de 2015.

Ahora bien, los Mapoyo han dado mayor relevancia al hecho mismo de la posesión de la espada, otrora perteneciente al "Padre de la Patria", quien junto con la espada, les otorgó el derecho a sus tierras. Según Jairo Bastidas, vocero Mapoyo, la espada "fue entregada a Paulino Sandoval, bisabuelo tatarabuelo que ya no existe. Desde ese entonces (1.700) viene asumiéndose y entregándosela a unas cuantas generaciones" ${ }^{5}$. Para los

5 Declaraciones disponibles en http://www.correodelorinoco.gob.ve/nacionales/pueblo-mapoyoespada-bolivar-nos-ha-defendido-por-decadas/ 


\section{Revista de Arqueologia Pública}

funcionarios públicos parece existir una necesidad de ratificar la autenticidad de la espada, de modo que según Irady ${ }^{6}$ en 1983 se realizaron las primeras investigaciones antropológicas y arqueológicas para determinar la fidelidad del armamento, y añade:

No hay duda de que es una espada que corresponde a la época"; es decir, al siglo XIX... el Libertador estuvo en la zona varias veces y que el momento en que toma la decisión de distribuir tierras entre el Ejército "curiosamente corresponde con esos años". El mito de la espada "está acompañado de las tierras", un elemento fundamental para los pueblos originarios. Los mapoyo ayudaron al prócer en una batalla que se habría efectuado entre los ríos Suapure y Parhuaza para recuperar una fortaleza... y hay documentos que demuestran que existió la fortaleza, e inclusive que en esa fortaleza aparentemente llegaba a fundirse metal (IRADY, en CORREO DEL ORINOCO, 2014).

En el entramado narrativo referente a la espada de Bolívar se mezcla una perspectiva "materialista" con una "constructivista" en relación a la autenticidad, la primera claramente se argumenta con el interés en los criterios que permitan vincular la posible datación del objeto, con sus características particulares que la hacen una "espada del siglo XIX". Aún cuando no se hayan realizado "pruebas científicas" para la medición de su antigüedad, hay claramente un énfasis en los orígenes y esencias. La autenticidad de acuerdo con Latour (1993) es una de las prácticas que definen a la modernidad, a través de la producción de orden, el trabajo de purificación y más aún, la supresión de la heterogeneidad e hibridismo (en JONES, 2010). Ahora bien, la autenticidad más que ser algo que se pueda comprobar inherente al objeto, es una cualidad culturalmente construida que es atribuida de acuerdo con regímenes de significado. También se puede relacionar a la dimensión de intercambio contextual (HOLTORF, 2005). Sin embargo, resulta de gran importancia también dar atención a la materialidad, porque lo contrario sería pretender que la autenticidad pudiera ser simplemente atribuida en cualquier objeto, sin importar su historia particular. Perspicazmente Jones nos señala que el proceso de negociación de la autenticidad de los objetos puede ser una manera de establecer la identidad de los individuos (JONES, 2010: 189), siendo que tanto la experiencia única de un objeto como sus relaciones con personas y lugares, actuales o del pasado, podría permitir que las personas que establezcan una comunión personal (el autor habla de contacto físico y experiencia íntima) con dicho objeto puedan participar de su autenticidad.

6 Presidente Del Centro de Diversidad Cultural. Declaraciones disponibles en: https://issuu.com/correo del orinoco/docs/co1859 


\section{Revista de Arqueologia Pública}

Esta reflexión además de resaltar la función de la autenticidad de los objetos en la negociación de la propia autenticidad de los individuos, un elemento constante en la trayectoria cultural de los Mapoyo, nos refiere que la relación pasado-presente en la experiencia del objeto en sí mismo, debe ser tomada en cuenta. De hecho, eso ayudaría a entender el rol del "aura" de los objetos históricos, como participantes de eventos que en el presente, se transforman en momentos icónicos. Por ejemplo, Irady destacó en una rueda de prensa que era una "espada usada en batalla por el Libertador"7. Por una parte habría que destacar el papel de la negociación de la autenticidad de los objetos en la relación entre las cosas, las personas y los lugares, tal como es comentado por Jones (2010), pero también en el marco de referencia de los procesos nacionales específicos, con sus discursos cosmogónicos.

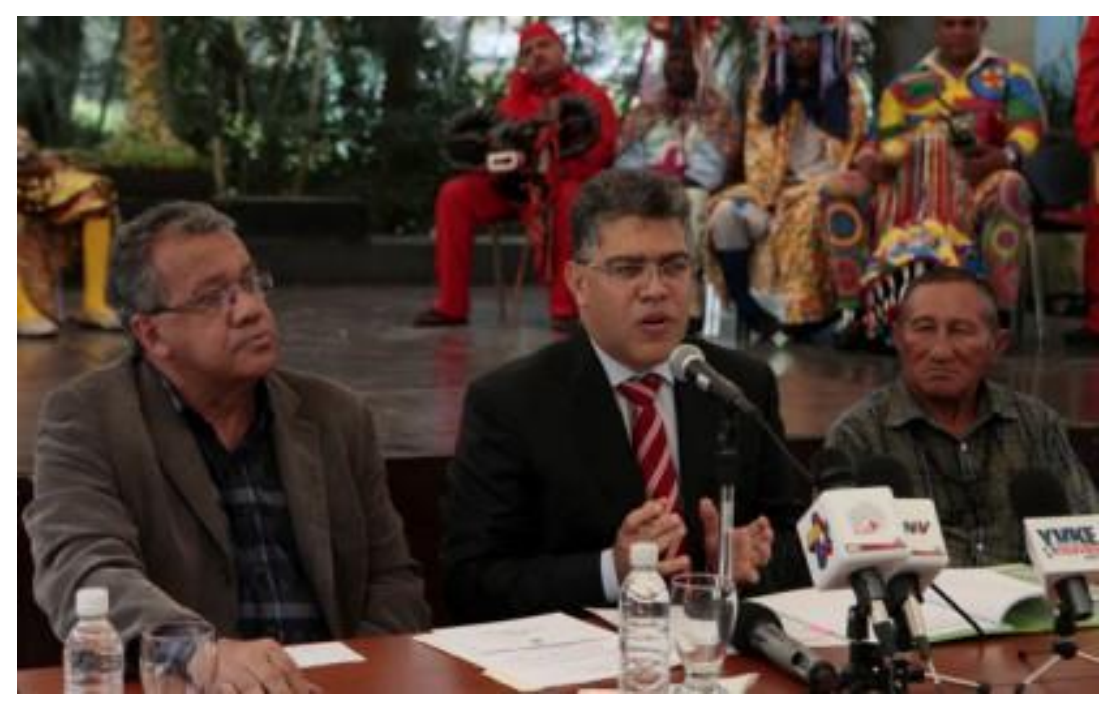

Figura 4: Benito Irady, EliasJaua (para ese momento Vicepresidente de la República) y Capitán Simón Bastidas en el Centro de Diversidad Cultural. Imagen tomada de http://www.telesurtv.net/news/Proponen-preservar-memoria-cultural-de-los-Mapoyo-201408070081.html. Accesado: 2 de agosto de 2015.

Jelin comenta que en los procesos decimonónicos de formación del Estado, la construcción del "gran relato de la nación" a través de los símbolos patrios, monumentos, panteones de héroes nacionales y una versión de la historia, tuvieron un papel fundamental en las operaciones simbólicas ligadas al "anclaje de la identidad nacional" (2001: 40). De manera similar podemos decir que un proceso de neo-nacionalismo de corte patriota se ha

${ }^{7}$ Declaración en: https://issuu.com/correo_del_orinoco/docs/co1859

\begin{tabular}{|l|l|l|l|l|l|l|}
\hline (C) Rev. Arqueologia Pública & Campinas, SP & v. 10 & n. 3 & p. 91-113 & OUT. 2016 & ISSN 2237-8294
\end{tabular}




\section{Revista de Arqueologia Pública}

ido tejiendo en Venezuela a partir del proyecto Bolivariano, se ha producido una "etnización de lo nacional, con una búsqueda renovada (o reconstitución) de las raíces étnicas", que sin embargo también incorpora "nacionalización de lo étnico" (Machuca, 2010: 26). Además es de notar el potencial simbólico aliado a la insurgencia, de la materialidad que comporta la espada y la "memoria colectiva" convertida en patrimonio cultural para la legitimación de los conceptos en los que se basa el discurso gubernamental nacionalista, que resulta de relevancia fundamental para la concretización de beneficios prácticos y capital político para los Mapoyo.

De alguna forma esto se puede entender desde la reflexión de Castillo et al (1996), quienes refieren que la ideología, como integrante de la cultura, es componente fundamental de las interacciones humanas y estrategias de poder que configuran los sistemas sociopolíticos; la ideología, para ellos, es siempre materializada, incorporada en formas concretas, para que pueda tornarse parte de la cultura de colectivos humanos.

El análisis de la patrimonialización de la tradición Mapoyo nos lleva a interceptar la noción de "empresarios de la memoria", agentes que reclaman el reconocimiento de cierta versión del pasado, con las conveniencias de legitimación del Estado y de instituciones culturales. Son varios niveles de acción y múltiples actores, en pugna y en conciliación sobre las representaciones del pasado que se vuelven oficiales. Las narrativas, al revestirse de una autoridad externa, se vuelven factuales, se reivindican como estandartes. Según Poulot (2009: 36): "la historia del patrimonio es la historia de la construcción del sentido de identidad y más particularmente, aquella de los imaginarios de "autenticidad" que inspiran las políticas patrimoniales".

Ciertamente como indica este mismo autor, en la retórica de las luchas identitárias, no necesariamente han de coincidir los relatos locales con los análisis históricos o etnográficos, pues hasta si carecen de verosimilitud, se muestran eficaces (POULOT, 2008). En el documento citado del IPC destacan que este relato es "fundamental para autoreconocerse como parte integrante de la Nación". Sin embargo, esta interpretación está orientada por la búsqueda de la incorporación por parte del gobierno actual de la tradición oral Mapoyo, como símbolo legitimador de la articulación de "grupos indígenas" con las luchas independentistas, atravesando pasado y presente como una frontera convenientemente permeable.

Es claro que además de la retórica estatal y de los discursos globales, un elemento destacado en este proceso de patrimonialización es la posibilidad de los Mapoyo hacer uso 


\section{Revista de Arqueologia Pública}

de un "recurso escaso" (APPADURAI, 2001) para principalmente, asegurar sus derechos territoriales. Vale destacarse que como plantea Candau (2011), "las identidades no se construyen a partir de un conjunto estable y objetivamente definible de "trazos culturales" sino que son producidas y se modifican en el cuadro de las relaciones e interacciones sociosituacionales". Estas interacciones que también se dan mediadas porcon objetos, como la espada de Bolívar, tomada como una materialización de la ideología, confiere la eficacia simbólica que tanto los Mapoyo como el estado Bolivariano precisan para la movilización de sus intereses.

Podríamos decir, entonces, que la espada de Bolívar está viva y animada, siendo estructurante de la ideología gubernamental, de la demarcación de las tierras y de la activación del patrimonio cultural Mapoyo. Como objeto del pasado, su eficacia simbólica reposa en el presente: ella es una espada de la conquista.

\section{Consideraciones finales}

Según Debary y Turgeon (2007), el amplio interés que la materialidad ha suscitado fuera de la arqueología y la antropología, que en cierta medida se adjudicaban la prerogativa de su análisis, muestra el reconocimiento cada vez más conspicuo del lugar de los objetos en las prácticas sociales contemporáneas. Igualmente ya desde Halbwachs (1994 [1925]) existe el entendimiento de que la llamada a la memoria colectiva gestiona el pasado a partir de los intereses del presente, particularmente de los grupos predominantes. En Venezuela, el grupo actualmente hegemónico maneja la retórica de reivindicación de los "subalternos", lo que sin embargo, no se traduce en una efectiva política descentralizadora, sino por el contrario, da continuidad al establecido mecanismo de funcionamiento de las políticas públicas a través del partidismo burocratizado. En el ámbito del patrimonio cultural no ha sido diferente, pues las postulaciones de qué "manifestación cultural" será escogida y exaltada, ha estado fuertemente influenciada por la articulación política que logren los sectores de las comunidades que tienen interés en llevar a cabo tal proceso, quienes tendrán entonces que conseguir la aprobación de las instancias institucionales estatales, muchas veces a partir de la adecuación al discurso oficialista. Así, el potencial simbólico del patrimonio cultural para la legitimación de los conceptos en los que se basa el discurso gubernamental nacionalista resulta de relevancia fundamental para la concretización del status patrimonial. 


\section{Revista de Arqueologia Pública}

Las perspectivas identitárias de los Mapoyo han transitado históricamente posturas de adherencia a prácticas tradicionales, eventualmente incorporándoles componentes noindígenas (SCARAMELLI Y TARBLE, 2000), así como también en otros momentos ha contemplado la apertura hacia cosmovisiones estatales y académicas. Son relaciones multidireccionales que les han permitido mantenerse a flote frente a un panorama que desde los años 40's los declaraban "aculturados" y en "vías de desaparición" (CRUXENT, 1948; PERERA, 1992) y por tanto, sin "derechos territoriales indígenas". Acertadamente los líderes Mapoyo empreendieron lo que llamaron una "revitalización cultural” (DURAN, 2008), donde su "memoria colectiva" así como los referentes materiales que le amparan, han sido esenciales para su negociación con la sociedad nacional. Podríamos decir que en la actual arena política de Venezuela, el capital simbólico de una "memoria indígena" así como de una "memoria patriota" y especialmente, la autenticidad que la materialidad de la espada de Bolívar le otorga a la narrativa, tuvo influencia en que el Estado venezolano decidiera proponer la nominación de las tradiciones orales Mapoyo ante la UNESCO.

Por su parte, el proceso de activación patrimonial, tanto de las tradiciones orales como de la previa construcción de un Museo Comunitario, tuvo gran relevancia en la aprobación de la titularidad territorial. De tal manera, podríamos decir que los Mapoyo, han tenido una larga y compleja historia de interacciones sociales y políticas en las que han conseguido manejar categorías propias en el ejercicio de su agencia, a la vez que también ha resaltado la capacidad de acción de la espada de Bolívar resguardada por este grupo, en tanto su biografía cultural le lleva a constituirse como un "recurso escaso" (APPADURAI, 2001) con capital simbólico, que se traduce en capital político. Además ha establecido el vínculo de eficiente articulación con las concepciones oficialistas de las instituciones culturales del país, tanto como con los discursos y prácticas globales de la UNESCO. Es clara entonces la inherencia política y material de la patrimonialización, pero a quiénes servirá en el futuro a mediano plazo y en qué medida, dependerá de múltiples factores que se construyen diacrónicamente, se re-semantizan constantemente y fluctúan en las finas arenas de la situacionalidad.

\section{Referencias bibliográficas}




\section{Revista de Arqueologia Pública}

ABREU, R. Museus indígenas no Brasil: notas sobre as experiências Tikuna, Wajãpi, Karipuna, Palikur, Galibi-Marworno e GalibiKali'na. En FAULHABER, BERTOL \&BORGES (orgs.) Ciências e Fronteiras. Museu de Astronomia e afins. Rio de Janeiro. 2012. P.10-20.

ABU-LUGHOD, J. Culture, globalization and the world-system. Macmillan. Londres. 1991.

ANGOSTO, L. Pueblos indígenas, guaicaipurismo y socialismo del siglo XXI en Venezuela. En Antropológica n. 110, p. 9-33. 2008.

ANGOSTO, L. Pueblo indígenas, multiculturalismo y la nueva geometría del poder en Venezuela. En Cuadernos del CENDES, Año 27, n73, Enero-Abril 2010. Pp.97-132.

APPADUARI, A. La vida social de las cosas. Perspectiva cutural de las mercancías. Editorial Grijalbo. México. 1991.

APPADURAI, A. The globalization of archaeology and heritage. A discussion with Arjun Appadurai. En Journal of Social Archaeology. Vol 1 (1)35-49. 2001.

ARANDA, G Y SALINAS, S. Bolívar según Chávez. Ensayo de una tendencia. RIL Editores. Santiago. 2013.

BAUDRILLARD, J. Le system des objects. Gonthier. Paris. 1968.

BEAUDRY, M, ET AL. Artifacts and active voices: material culture as social discourse. En The archaeology of inequality, McGuire, R y Paynter, R (eds.) Blackwell. Oxford. 1991.

BOCCARA, G e AYALA, P. Patrimonializar al indígena. Imaginación del multiculturalismo neoliberal en Chile. Cahiersdes Amériques latines n.67, p. 207-227. 2012.

BORTOLOTTO, C. UNESCO, cultural heritage, and outstanding universal value: value based analyses of the World Heritage and Intangible Cultural Heritage Conventions. International Journal of Heritage Studies. 21:5, 528-53. 2015.

CANCLINI, N. Los usos sociales del Patrimonio Cultural. En Aguilar Criado, E. Cuadernos Patrimonio Etnológico. Nuevas perspectivas de estudio. Consejería de Cultura. Junta de Andalucía. 1999. Pp. 16-33

CANDAU, J. Memória e identidade. Editora Contexto. São Paulo. 2011.

CASTILLO, J; DeMARAIS, E y EARLE, T. Ideology, materialization and power strategies. EnCurrent Anthropology 37 (1):15-31. 1996.

CLIFFORD, J. Four Northwest Coast Museums: Travel Reflections. En Karp, I y Lavine, Exhibiting Cultures: Poetics and Politics of Representation. Smithsonian Institution. Washington. 1991.

CLIFFORD, J. The predicament of culture. Harvard University Press. 1988.

COMAROFF, J y COMAROFF, J. Etnografia e imaginação histórica. Tradução de Dulley, I e Janequine, O. Em Revista Proa, N2 (1):1-72, 2010.

\begin{tabular}{|l|l|l|l|l|l|l|} 
(C) Rev. Arqueologia Pública & Campinas, SP & v. 10 & n. 3 & p. 91-113 & OUT. 2016 & ISSN 2237-8294
\end{tabular}




\section{Revista de Arqueologia Pública}

CRUXENT, J, M. Datos demográficos. En Memorias de la Sociedad de Ciencias Naturales La Salle 21: 64-68, 1948.

DEBARY, Octave. Segunda mão e segunda vida: objetos, lembranças e fotografias. In: Revista Memória em Rede: Pelotas, v.2, n.3, ago-nov. 2010.

DIETLER, M. A tale of three sites: the monummentlization of Celtic opidda and the politics of colective memory and identity. World Archaeology 30, vol 30 (1) 72-89. 1998.

DOUGLAS, M Y ISHERWOOD, B. The world of goods. Toward an anthropology of consumption. Routledge. 1996.

DURÁN, R. (2008). WihiMopue (Soy Mapoyo): El Diseño de un Museo Comunitario en la Comunidad Indígena Mapoyo de El Palomo, Edo. Bolívar y su Utilización como Instrumento de Legitimación del Pasado y Reafirmación Identitaria. Trabajo Final de Grado, Escuela de Antropología, Universidad Central de Venezuela, Caracas, Venezuela.

FERREIRA, L.M. Essas coisas não Ihes pertencem: relação entre legislação arqueológica, cultura material e comunidades. Revista de Arqueologia Pública, Campinas, 7: 87-106. 2013.

FOUCAULT, M. Bio-Histoire et Biopolitique. In: Dits et Écrits. Paris: Gallimard. Vol III, 1994, pp. 95-97.

GNECCO, C. Multivocalidad anos después. En RIVOLTA, M, MONTENEGRO, M, MENEZES FERREIRA, L Y NASTRI, J. Multivocalidad y activaciones patrimoniales en arqueología: perspectivas desde Sudamérica. Fundación de Historia Natural Félix de Azara. Buenos Aires. 2014. p. 35-46.

GOSDEN, C. (2005): What do Objects Want? Journal of Archaeological Method and Theory, (12): 3, 93-211, 2005.

HALBWACHS, M. Les cadres sociaux de la mémoire. Albin Michel. Paris. 1994.

HENLEY, P. Los Wanai (Mapoyo). En Los Aborígenes de Venezuela, vol 2. Walter Coppens Editor. Fundación La Salle. Caracas. 1975.

HODDER, I. Cultural Heritage Rights: From Ownership and Descent to Justice and Wellbeing. Anthropological Quarterly vol 83 (4) pp.861-882. 2010.

HODDER, I. Entangled: An Archaeology of the Relationships between Humans and Things. Wiley-Blackwell, Oxford, 2012.

HODDER, I. The Entanglements of Humans and Things: A Long-Term View. New Literary History, Volume 45, Number 1, Winter pp. 19-36, 2014,

\begin{tabular}{|l|l|l|l|l|l|l|} 
(C) Rev. Arqueologia Pública & Campinas, SP & v. 10 & n. 3 & p. $91-113$ & OUT. 2016 & ISSN 2237-8294
\end{tabular}




\section{Revista de Arqueologia Pública}

HOLTORF, C (2005) From Stonehenge to Las Vegas: Archaeology as Popular Culture. WalnutCreek, CA: Altamira Press.

INGOLD. T. Materials against materiality. En Archaeological dialogues 14 (1) 1-16. 2007.

JELIN,E. Los trabajos de la memoria. Siglo Veintiuno editores, España 2001.

JONES, A. Memory and Material Culture. Cambridge U. P, Cambridge, 2007.

JONES, S. Negotiating Authentic Objects and Authentic Selves. Journal of Material Culture, (15): 2, 181-203, 2010.

KNAPPET,C Y MALAFOURIS, F. Material agency: towards an non-anthropocentric approach. Springer. New York. 2008.

KOCKELMAN, P. Agency. The relation between meaning, power and knowledge. En Current Anthropology 48(3) 375-401. 2007.

KOPYTOFF, I. A biografia cultural das coisas: a mercantilização como processo. In: APPADURAI, A. 2008. A vida social das coisas: as mercadorias sob uma perspectiva cultural. Niterói: EdUFF, 2008.

LATOUR, B. Reemsamblar lo social: una introducción a la teoría del actor-red. Manantial. Buenos Aires. 2005.

LIZARRALDE, R. Mapa etnográfico de Venezuela y Regiones adyacentes. En Antropológica, 29, 1971.

LOWENTHAL, D. Why Sanctions Seldom Work: Reflections on Cultural Property Nationalism. International Journal of Cultural Property, (12): 393- 423. 2005.

LOWENTHAL, D. The Heritage Crusade and the Spoils of History. Cambridge: Cambridge University Press, 1998.

MACHUCA, Jesús A. Patrimonio y retradicionalización en la cultura indígena y popular en Mexico In: FERREIRA, Maria L., MICHELON, Francisca F. Memória, patrimônio e Tradição. Pelotas, Edufpel, 2010.

MARX, K. O Dezoito Brumário de Luís Bonaparte. En: Karl Marx e Friedrich Engels: Obras Escolhidas. São Paulo: Editora Alfa-Ômega, S/D, pp. 14-35.

MAZZUCHI, M.L e HEIDEN, R. Políticas Patrimoniais e reinvenção do passado: os pomeranos de São Lorenço do Sul, Brasil. In Cuadernos de Antropología Social, N30, PP.137-154. 2009.

MAUSS, M. Essaisur le don: forme e raison de l'échangedans les societés archaiques. En Sociologie et antropologie. Paris. 1950. 


\section{Revista de Arqueologia Pública}

MILLER, D. Shopping, place and identity. Londres. Routledge. 1998.

MINTZ, S. Sweetness and power. The place of sugar in modern history. Penguin Books. New York. 1985.

MOSONYI, E. E., \& SUÁREZ LUQUE, M. (2009). Los Mapoyo: Un Pueblo Patriota Ignorado. Zona Tórrida(4), 21-28.

OLSEN, B. In defense of things. Archaeology and the Ontology of Objects. AltaMira, Lanham, Maryland, 2010.

ORTIZ, R. Otro territorio: ensayos sobre el mundo contemporáneo. Convenio Andrés Bello.1998.

PERERA, M. Á. (1992). Los últimos Wánai (Mapoyos): Contribución al conocimiento indígena de otro pueblo amerindio que desaparece. Revista Española de Antropología Americana, 22, 139-161.

POULOT, D. Um Ecossistema do Patrimônio. In: CARVALHO, C. S. de;

GRANATO, M; BEZERRA, R. Z; BENCHETRIT, S. F. (orgs.). Um Olhar Contemporâneo sobre a Preservação do Patrimônio Cultural Material. Rio de Janeiro: Museu Histórico Nacional, pp. 26-43. 2008.

RUETTE, K. The Left-turn of Multiculturalism: indigenous and afrodescendant social movements in northwestern Venezuela. Ph. D Dissertation School of Anthropology. University of Arizona 2011.

SAHLINS, M. Cosmologies of Capitalism: the trans-pacific sector of the 'World System'. En N. Dirks, G. Eley y S. Ortner (eds.), Culture/Power/History: A reader in contemporary social theory. Princeton University Press. 1994.

SCARAMELLI, F., \& TARBLE, K. (2000). Cultural Change and Identity in Mapoyo Burial Practice in the Middle Orinoco, Venezuela. Ethnohistory, 47(3-4), 705-729.

STAVRAKAKIS, Y. The lacanian subject: the impossibility of identity and the centrality of identification. In: STRAVAKAKIS, Y. Lacan \& the political. London: Routledge, 1999. 13-39 p.

TILLEY, C. 2006. Identity, Place, Landscape and Heritage. Journal of Material Culture, (11): 1/2, 7-32.

TORNATORE, J.L. Patrimônio, memória, tradição, etc: discussão de algumas situações francesas da relação com o passado. In Revista Memória em Rede. Pelotas, v.1, n.1, dez.2009.

TURGEON, Laurier. La mémoire de la culture matérielle et la culture matérielle de lamémoire. In: DEBARY, Octave e TURGEON, Laurier. Objets e mémoires. Quebéc: Les Presses de l'Université Laval, 2007, pp. 13-32

\begin{tabular}{|l|l|l|l|l|l|l|} 
(C) Rev. Arqueologia Pública & Campinas, SP & v. 10 & n. 3 & p. 91-113 & OUT. 2016 & ISSN 2237-8294
\end{tabular}




\section{Fuentes digitales consultadas}

CRESPO, L.A. Declaraciones. Disponible en: http://www.telesurtv.net/news/Jubilo-pordeclaracion-de-Unesco-sobre-Mapoyo-20141125-0091.html Accesado: 15 de mayo de 2015.

Capitán Simón Bastidas con la espada de Bolívar frente al Panteón Nacional. Imagen tomada de http://www.correodelorinoco.gob.ve/nacionales/pueblo-mapoyo-espada-bolivarnos-ha-defendido-por-decadas/. Accesado: 14 de abril de 2015.

Capitán Simón Bastidas en un acto oficial, mostrando la espada de Bolívar y la daga de Páez. Imagen tomada de http://www.telesurtv.net/news/Proponen-preservar-memoriacultural-de-los-Mapoyo-20140807-0081.html Accesado: 2 de agosto de 2015.

IRADY, B. Entrevista en Correo del Orinoco, 2014. Disponible en http://www.correodelorinoco.gob.ve/wp-content/uploads/2014/11/Web-LA2141.pdf Accesado2 de agosto de 2015. 